\title{
ДОСТУПНОСТЬ МЕДИЦИНСКОЙ ПОМОЩИ: РОССИЯ В ЕВРОПЕЙСКОМ КОНТЕКСТЕ
}

В статье сравнивается доступность медицинской помощи в России и в ряде европейских стран, входящих в ЕС. К числу ключевых индикаторов, определяющих возможность получить и использовать медицинские услуги, выбраны следующие: охват населения, получающего медицинскую помощь на основе государственного страхования; объем личных платежей домохозяйств за медицинскую помощь; территориальное распределение врачей; оценка неудовлетворенных потребностей населения в сфере медобслуживания. Сравнительный анализ доступности услуг здравоохранения в России и европейских странах на основе этих показателей позволил прийти к следующим выводам. Медицинская помощь в России, как и в подавляющем большинстве европейских стран, охватывает практически все население страны. Однако базовый пакет медицинских услуг, гарантируемый государством, в нашей стране не соответствует потребностям населения в медицинской помощи. Об этом свидетельствует неуклонное возрастание за последние 15 лет доли личных расходов российского населения в общем объеме финансирования на поддержание здоровья, тогда как в большинстве стран ЕС эти доли оставались стабильными. Такая тенденция неизбежно приводит к углублению неравенства в доступности услуг здравоохранения, формируя все более выраженные финансовые барьеры в доступе для низкостатусных слоев общества. Анализ территориального распределения врачей позволяет сказать, что в России обеспеченность населения докторами в городах значительно выше, чем в селах, в то время как в странах Евросоюза наблюдается более равномерное распределение медицинского персонала. Оптимизация кадровых ресурсов здравоохранения, проводившаяся в последние годы, не выводит Россию на среднеевропейский уровень по обеспеченности высококвалифицированным

Людмила Васильевна Панова- к.э.н., старший научный сотрудник, Социологический институт Федерального научно-исследовательского социологического центра Российской академии наук, Санкт-Петербург, Россия. Электронная почта: 1_panova@list.ru 
медицинским персоналом сельского населения. Неудовлетворительная организация медицинской помощи для аграрных территорий, в том числе недостаточное количество врачей, затрудняет территориальную доступность медицинских услуг для деревенского жителя. Сопоставление оценок неудовлетворенных потребностей в медицинской помощи российских и европейских граждан свидетельствует о том, что доля россиян, указывающих на невозможность получения медицинской помощи из-за проблем транспортной доступности или высокой стоимости услуг, во много раз выше, чем в странах Европы.

Ключевые слова: доступность, медицинская помощь, барьеры, ЕС, Россия

DOI: 10.17323/727-0634-2019-17-2-177-190

Доступ к медицинской помощи выполняет важнейшую функцию в профилактике, лечении и укреплении здоровья, но наряду со сбережением здоровья, доступность медицинских услуг является значимым фактором решения многих социальных проблем. Своевременное предупреждение болезней и качественное лечение отражаются в уменьшении уровня неравенства в здоровье, что само по себе влияет на сокращение бедности, благоприятствует снижению социальной изоляции, поддерживает социальную интеграцию общества. Доступ к медицинскому обслуживанию тем самым является одним из важнейших компонентов права на здоровье. Признание права на охрану здоровья и медицинскую помощь во всех конституциях европейских стран означает, что государство несет отвественность за предоставление доступа к надлежащим услугам здравоохранения для всех граждан. Политика государства, направленная на достижение этой цели, стремится обеспечить всеобщий охват услугами медобслуживания всех граждан, приоритетное финансирование здравоохранения, оптимальное распределение ресурсов здравоохранения и преодоление барьеров, препятствующих получению медицинской помощи.

Настоящее исследование посвящено сравнительному анализу доступности медицинской помощи в России и в странах Европейского союза. В предпринятом анализе выявляются основные индикаторы доступа к медпомощи и рассматриваются особенности получения услуг здравоохранения в нашей стране на фоне общеевропейских тенденций. Измерение доступа является многомерной задачей, поскольку в этой области отсутствует всеохватывающий, универсальный индикатор, но разработаны показатели, раскрывающие различные аспекты доступности услуг медобслуживания. Аналитический обзор теоретических положений, посвященный возможности получить медицинскую помощь и системе Европейских основных показателей здоровья $(E C H I)$, помогают определить критерии, которые могут быть использованы для оценки доступности услуг здравоохранения (European Commission 2013; Gelormino et al. 2011; 
Allin et al. 2007; Wörz et al. 2006). Так, система ECHI, охватывает все сферы общественного здоровья и здравоохранения и акцентирует внимание на следующих тематических разделах (Lalonde 1974): состоянии здоровья, детерминантах здоровья, услугах здравоохранения, демографических и социально-экономических характеристиках населения. Доступность медицинской помощи рассматривается как значимая детерминанта здоровья, а в число индикаторов доступа включены барьеры, мешающие получению необходимых услуг.

На основе указанного подхода к числу ключевых индикаторов доступа к медуслугам в этой работе отнесены: охват населения, получающего медицинскую помощь на основе государственного страхования; объем личных платежей домохозяйств за медицинское услуги и приобретение лекарственных товаров; территориальное распределение врачей; и оценка неудовлетворенных потребностей населения в сфере медицинской помощи. Анализ этих показателей дает основания для сравнения доступности медицинской помощи между Россией и странами, входящими в Европейский союз. Информационную базу исследования составили российские и европейские статистические данные.

\section{Охват населения государственными услугами здравоохранения}

Универсальный охват населения услугами здравоохранения рассматривается как базисная характеристика медицинского обслуживания во всех странах европейского региона. Достижение этого показателя организации здравоохранения оценивается по трем направлениям: доля населения, имеющего право на получение государственных услуг здравоохранения; спектр услуг, предоставляемых государством; уровень личных платежей граждан за медицинскую помощь. Россия и большинство европейских стран достигли практически всеобщего охвата населения медицинской помощью, по крайней мере, для основного набора услуг, за счет бюджетного финансирования. В нашей стране бесплатную медицинскую помощь на основании Программы государственных гарантий могут получить 145,8 млн российских граждан $(99,66 \%)$, т. е. практически все жители, застрахованные в системе ОМС (Счетная палата РФ 2015).

Из 28 государств, входящих в ЕС, чуть меньше половины (тринадцать стран) имеют полный охват населения медицинской помощью за счет страхования или государственного бюджета. Причем в эту категорию попадают не только страны с высоким уровнем экономического развития, например, Дания, Финляндия, Швеция, Великобритания, но и Чехия, Литва, Хорватия, где ВПП на душу населения значительно ниже. В диапазоне близком к универсальному охвату (99,0-99,8\%) располагаются Австрия, Франция, Испания, Германия, Нидерланды, Бельгия. В интервале 
91-96\% охваченного населения находятся пять стран: Польша, Эстония, Словакия, Венгрия, Люксембург. В четырех - больше десяти процентов жителей не имеют медицинской страховки для основного набора услуг, к их числу относятся Болгария (88,2\%), Греция (86\%), Румыния (86\%) и Кипр (83\%) (OECD 2016а). Очевидно, что большинство европейских стран придерживаются политики всеобщего охвата населения медицинской помощью, как и в России, где граждане имеют право на получение гарантированных государством услуг здравоохранения.

Вторая характеристика универсального охвата населения состоит в оценке спектра услуг, предоставляемых программами государственных гарантий. Ни в одной стране, даже с высоким уровнем дохода, гарантированная бесплатная помощь не включает все возможные услуги и, следовательно, не оплачивается стопроцентная стоимость без совместного несения расходов пациентами. В определенной мере, набор гарантированных услуг зависит от организации медицинского обслуживания в различных странах, но главным образом, от способности и желания государства освободить население от платы за предоставление помощи, т.е. в конечном счете, от политических приоритетов правительства.

В России в рамках Программы государственных гарантий (ПГГ) бесплатно предоставляются первичная специализированная помощь в амбулаторных и стационарных условиях и скорая помощь (Правительство РФ 2016). В европейских странах, независимо от моделей здравоохранения (национальной, финансируемой в основном из бюджета, или страховой с многоканальным финансированием), в гарантированную программу входит перечень услуг очень похожий на российский, поскольку при создании ОМС в значительной степени ориентировались на страны Европы. Однако наполнение пакета бесплатной медицинской помощи может быть разным в зависимости от списка выделяемых услуг, финансируемых государством. Например, в России лекарства при амбулаторном лечении для большинства населения не входят в ПГГ, пользование фармацевтическими препаратами в основном происходит за собственные средства пациентов. В то же время в европейских странах широко распространено использование механизма совместного несения расходов по различным видам помощи. Поскольку гарантированный набор медицинских услуг не всегда удовлетворяет все без исключения потребности пациентов в медобслуживании, важно понимать, насколько объем бесплатного базового пакета требует дополнительных личных расходов населения на получение высококачественной медицинской помощи. В том случае, когда охват услугами здравоохранения является эффективным, население должно иметь доступ к необходимой медицинской помощи, не оказываясь в ситуации финансовых лишений. Все это приводит к третьему индикатору доступности медицинской помощи - анализу личных расходов домохозяйств за медицинские услуги. 


\section{Личные расходы}

Прямые личные расходы населения на использование медицинской помощи вызывают пристальное внимание исследователей в связи с анализом финансовой защищенности домохозяйств и оценкой денежных барьеров при использовании услуг медицинского назначения. В случае значительной доли прямых личных платежей в объеме общего финансирования здравоохранения, тяжесть этих расходов смещается в сторону низко статусных групп и снижает финансовую защищенность наиболее уязвимых слоев, что может сопровождаться даже отказом от необходимой медицинской помощи (Шишкин и др. 2014; Eurofound 2014).

Анализ расходов на здравоохранение, оплачиваемых непосредственно пациентами, показывает, что в среднем по странам ЕС на протяжении последних лет отмечается небольшое снижение этого показателя. Если в 2000 г. личные расходы составляли 17,6\% в общем объеме затрат на здравоохранение, то в 2014 г. они были равны 16,7\% (WHO 2016). Расходы пациентов из собственных средств значительно различаются по европейским странам. Так, в 2014 г. самая высокая доля личных платежей от общего финансирования здравоохранения отмечалась на Кипре (48,7\%), в Болгарии $(44,2 \%)$, Латвии $(35,1 \%)$ и Греции $(34,9 \%)$. Самый низкий уровень наблюдался в странах, вошедших в ЕС до 2005 г.- Нидерландах (5,2\%), Франции $(6,3 \%)$ и Великобритании $(9,7 \%)$. Оценивая изменения финансовой политики государств на протяжении длительного отрезка времени (2000-2014 гг.), следует отметить, что в ряде стран Евросоюза прилагались усилия по снижению личных трат домохозяйств на медицинскую помощь. Пятнадцать стран за эти годы уменьшили прямые расходы семей на здравоохранение на 10-20\%, однако в десяти странах наблюдалось небольшое увеличение этого показателя на 10-13\% (там же).

Положение России значительно отличается от большинства европейских стран. В 2000 г. личные платежи составляли $30 \%$ общего объема финансирования здравоохранения. Увеличение доли расходов, оплачиваемых непосредственно пациентами, продолжало нарастать и в 2010 г. этот показатель был равен 36\%, а к 2014 г. платежи домохозяйств составили почти половину всех расходов на здравоохранение- 45,9\% (там же). Иначе говоря, за последние 15 лет наблюдается значительный и неуклонный рост личных расходов россиян в общем объеме затрат на поддержание здоровья. Это свидетельствует о том, что базовый пакет медицинских услуг, обеспечиваемый ПГГ, в нашей стране в значительной мере не соответствует потребностям населения.

Уровень финансовой нагрузки домохозяйств за счет трат на медицинскую помощь обычно измеряют долей личных платежей на эти цели в общем объеме потребления домохозяйств. В нашей стране этот показатель в 2007 г. составлял 3 \%, а в девятнадцати странах ЕС, представленных 
в исследовании OECD за этот тоже период,- 2,8\% (Росстат 2007; OECD 2009). Но процесс постоянного увеличения личных платежей населения в общем объеме финансирования здравоохранения в России сопровождался ростом финансовой нагрузки домохозяйств, и в 2014 г. этот показатель составил 3,5\% (Росстат 2015). В странах ЕС, за тот же период, доля в общем объеме потребления расходов, затрачиваемых населением на медицинскую помощь, уменьшилась на полпроцента и была равна 2,3 \% (OECD 2016а). Имеются существенные различия между странами, так в 2014 г. в пределах двух процентов на медицинскую помощь от общего потребления домашних хозяйств тратило население Люксембурга, Франции, Великобритании, Хорватии. В следующий интервал, до 4\%, попадают жители большинства стран, в том числе и Россия (рис. 1).

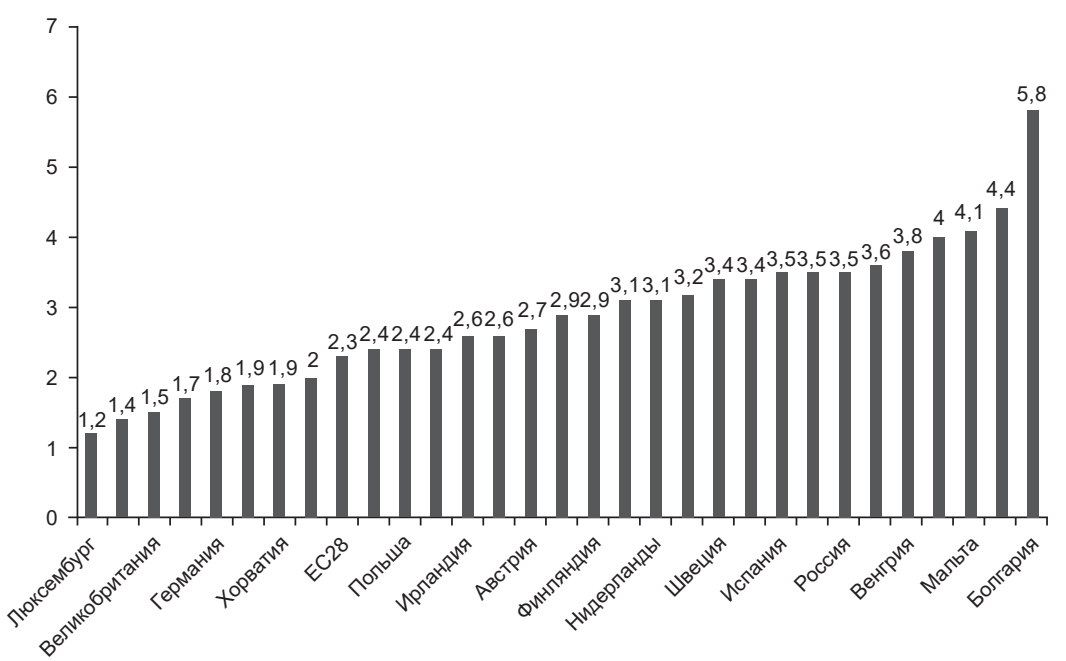

Рисунок 1. Личные расходы на здоровье в странах ЕС и России (\% от потребления домохозяйства 2014 г.). Источники: OECD 2016а, Росстат 2015

В целом можно сказать, что средний показатель финансовой нагрузки домохозяйств в целях сохранения здоровья в нашей стране находится на уровне большинства европейским стран. Однако финансовая безопасность низкостатусных групп обеспечена значительно слабее. В России 5,6\% домохозяйств несут катастрофические расходы, при которых тратится на медицинские услуги более $40 \%$ семейного бюджета, в то время как в большинстве стран Евросоюза такие серьезные финансовые трудности при обращении за медицинской помощью испытывают меньше одного процента семей (Xu et al. 2010). 


\section{Территориальное распределение врачей}

Проблема территориальной доступности врачей определяется в современной литературе как одна из ключевых в политике здравоохранения (Шейман, Шевский 2015; Ono et al. 2014). Особенно остро стоит вопрос о неравномерном пространственном размещении врачей между городами и сельскими поселениями. Недостаток персонала в сельской местности создает серьезные барьеры для доступа к медицинским услугам. Дисбаланс в территориальном распределении врачей проявляется во всех странах (рис. 2). В России в 2011 г. плотность врачей (количество врачей на 1000 жителей) в городах превышала сельские территории в 4,6 раза. Но проводимая в последние годы оптимизация регионального здравоохранения сопровождалась некоторым увеличением обеспеченности высококвалифицированным медицинским персоналом сельских территорий и сокращением этого показателя в городах. Так в 2014 г. плотность врачей в сельских поселениях составила 1,51 чел. на 1000 сельских жителей, а в городах 6,03 чел., разрыв несколько сократился. Эта тенденция сохранялась и в последующие годы: в 2016 г. количество врачей на 1000 жителей в городах превышало рассматриваемый показатель в сельской местности в 3,7 раза (Минсельхоз России 2018).

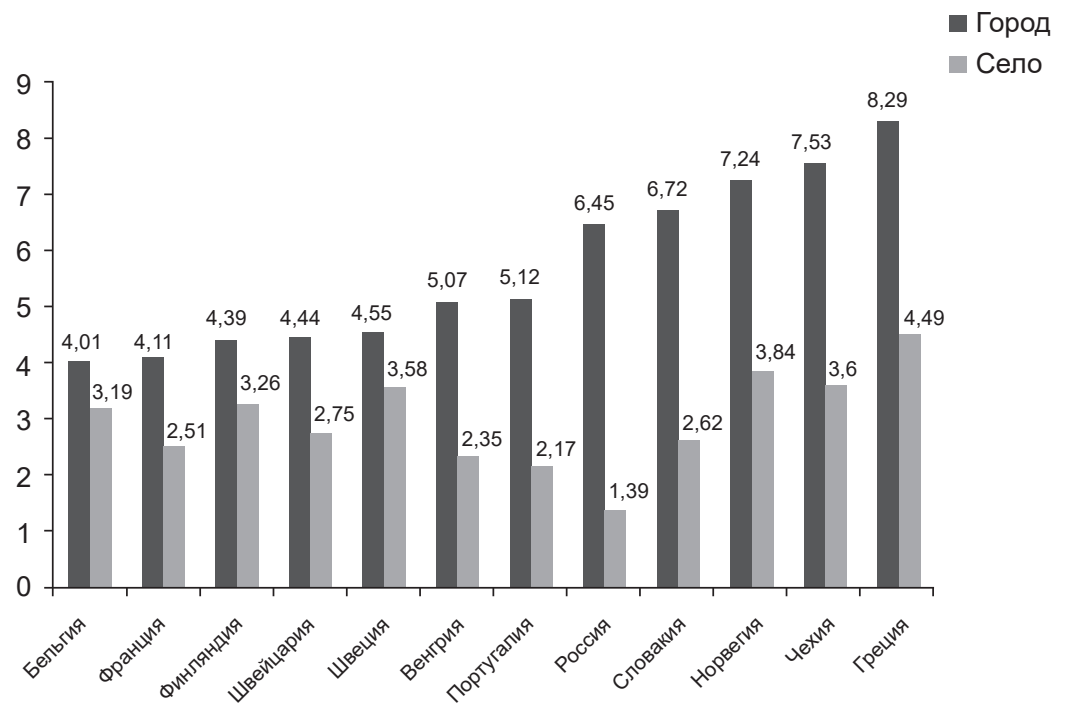

Рисунок 2. Обеспеченность врачами на 1000 городского/сельского населения в странах Европы и России 2011г. Источники: ОЕСD 2014; Минсельхоз России 2014.

По данным, опубликованным в региональных обзорах ОЭСР, различия в плотности врачей между городом и сельской местностью были самыми 
высокими (более чем в два раза) в Словакии, Чехии, Португалии и Венгрии. А небольшой разрыв (меньше чем в полтора раза) отмечается в двух северных странах - Швеции и Финляндии, и почти равное обеспечение высококвалифицированным медицинским персоналом в городе и селе фиксируются в Бельгии (OECD 2014). Сравнение России с Европой показывает, что оптимизация регионального здравоохранения, осуществлявшегося в последние годы, не выводит страну на среднеевропейский уровень по обеспеченности высококвалифицированным персоналом сельских жителей.

Такое размещение медицинских кадров в сельской местности создает неблагоприятную ситуацию с доступностью медицинской помощи, что и демонстрируют результаты опроса Всероссийского мониторинга социально-трудовой сферы села (Минсельхоз России 2014): по оценкам населения, даже фельдшерско-акушерские пункты, оказывающие минимальную первичную помощь, доступны далеко не всем сельским жителям. Больше трети респондентов $(35,2 \%)$ свидетельствуют об отсутствии элементарных медицинских услуг, каждый четвертый $(25,6 \%)$ оценивает медицинскую помощь как труднодоступную, и каждому десятому (9,6\%) она недоступна вовсе.

Здоровье населения зависит от многих факторов, но здравоохранение или отдельные его звенья оказывают непосредственное влияние на него, независимо от других воздействий. В итоге, такой показатель как продолжительность жизни значительно ниже среди сельского населения на фоне городских жителей России. Если в среднем по стране общая продолжительность жизни в 2011 г. составила 69,8 лет, то у сельских жителей этот показатель - 67,5 года. За последнее пятилетие наблюдается рост общей продолжительности жизни и в городе, и в сельских территориях, но разрыв остается значительным: так, в 2016 г. горожане живут почти на два года дольше, чем жители села (Росстат 2017).

\section{Неудовлетворенные потребности населения в сфере медицинской помощи}

В качестве обобщенного показателя, характеризующего доступность медицинских услуг, в настоящее время все шире используется индикатор, отражающий оценку гражданами неудовлетворенных потребностей в медицинской помощи (Chaupain-Guillot et al. 2015). К числу основных препятствий в получении медицинских услуг, связанных с институтами здравоохранения, обычно относят личные расходы домохозяйств на эти цели, отдаленность медицинских учреждений от места жительства и несвоевременность получения медицинской помощи по разным организационным причинам (длинные очереди на получение услуг, время ожидания приема врача или процедур, трудности предварительной записи на прием, отсутствие нужного специалиста). Источниками получения информации для такого исследования служат для России «Комплексное наблюдение 
условий жизни населения РФ» (Росстат 2014), а для стран ЕС-материалы обследований EU Statistics on Income and Living Conditions (Eurostat 2014).

В этом анализе проводится сравнение по двум показателям, оценивающим препятствия в удовлетворении потребности в медицинских услугах, а именно по транспортной доступности и личным платежам. Корректное сравнение по организационным барьерам, которые лежат в основе своевременности и приемлемости медицинской помощи для пациентов, невозможно в силу значительного отличия формулировки вопросов по этому показателю в анкетах в России и европейских странах.

Сопоставление российских и европейских данных свидетельствует, что в России доля респондентов, указывающих на невозможность получения медицинской помощи из-за проблем транспортной доступности или высокой стоимости услуг, значительно выше, чем в большинстве стран, входящих в ЕС. Если в России порядка четырех человек из ста сталкивались с этой проблемой, то в среднем в странах ЕС этот показатель был более чем в два раза меньше (1,7\%). Три страны фиксируют больший процент людей, чьи потребности не были удовлетворены по указанным причинам: Кипр (4,3 \%), Италия (6\%), Болгария (7,4\%). В диапазоне от двух до трех человек из ста находятся четыре страны (Венгрия, Франция, Ирландия, Португалия). Бо́льшая же часть стран ЕС указывает на незначительное число людей, которые испытают трудности с доступом из-за отдаленности медицинских учреждений от места жительства и недостатка личных денежных средств, таких было меньше одного процента. Так в Финляндии, Великобритании, Нидерландах лишь двое на тысячу испытывают эти трудности.

\section{Заключение}

Анализ доступности услуг здравоохранения в России и европейских странах позволил прийти к следующим выводам. Медицинская помощь в России, как и в подавляющем большинстве европейских стран, охватывает практически всё население. Однако базовый пакет медицинских услуг, обеспечиваемый программой государственных гарантий, не соответствует потребностям населения в медицинской помощи. Об этом свидетельствует значительное и неуклонное возрастание за последние 15 лет личных расходов российских граждан в общем объеме затрат на поддержание здоровья, тогда как в большинстве стран ЕС эти затраты оставались стабильными. Эта тенденция неизбежно приводит к углублению неравенства в доступности услуг здравоохранения, формируя все более выраженные финансовые барьеры в доступе для низкостатусных слоев общества.

Анализ территориального распределения врачей позволяет сказать, что в России обеспеченность докторами в городах намного превышает сельские территории, а в странах Евросоюза наблюдается более равномерное размещение медицинского персонала. Следует отметить, что оптимизация 
ресурсов здравоохранения, проводившаяся в последние годы, несколько сократила разрыв между плотностью врачей в сельских поселениях и городских агломерациях. Вместе с тем это улучшение не выводит нашу страну на среднеевропейский уровень по данному показателю. Недостаточное количество врачей не способствует улучшению территориальной доступности медицинских услуг для деревенских жителей.

Субъективная оценка неудовлетворенных потребностей в медицинской помощи рассматривается как заключительный этап в исследовании доступности медицинской помощи. Ограничением данной работы является невозможность изучения организационных барьеров, препятствующих получению медицинских услуг. Но даже анализ двух параметров неудовлетворенных потребностей- транспортной доступности и стоимости услуг- свидетельствует о том, что Россия значительно отстает от большинства европейских стран в этом аспекте.

В целом, по всем показателям доступности, за исключением доли охвата населения, Россия уступает большинству европейских стран. Проблемы со здоровьем в нашей стране в немалой степени обусловлены несовершенством организации здравоохранения, ее второстепенным приоритетом в области государственного финансирования, и слабым обеспечением доступа к её ресурсам для уязвимых слоев населения.

\section{Список источников}

Минсельхоз России (2014) Состояние сочиально-трудовой сферы села и предложения по ее регулированию. Ежегодный доклад по результатам мониторинга 2013 г. Вып.15. М.: Росинформагротех.

Минсельхоз России (2018) О состоянии сельских территорий в Российской Федерации в 2016 году. Ежегодный доклад по результатам мониторинга. Вып. 4-й. М.: Росинформагротех.

Правительство РФ (2016) О программе государственных гарантий бесплатного оказания гражданам медииинской помощи на 2017 год и на плановый период 2018 и 2019 годов. Доступно по ссылке: http://www.rgs.ru/upload/medialibrary/313/programma-gosudarstvennykhgarantiy-besplatnogo-okazaniya-grazhdanam-meditsinskoy-pomoshchi-na-2017-god-i-na-planovyyperiod-2018-i-2019-godov.pdf (дата обращения: 29 октября 2017).

Росстат (2007) Доходы, расходы и потребление домашних хозяйств в 2007 г. (по итогам выборочного обследования бюджетов домашних хозяйств). Доступно по ссылке: http:// www.gks.ru/bgd/regl/B07_102/Main.htm (дата обращения: 29 октября 2017).

Росстат (2014) Комплексное наблюдение условий жизни населения. Доступно по ссылке: http://www.gks.ru/free_doc/new_site/KOUZ14/survey0/index.html (дата обращения: 29 октября 2017).

Росстат (2015) Доходы, расходы и потребление домашних хозяйств в 2015 г. (по итогам выборочного обследования бюджетов домашних хозяйств). Доступно по ссылке: http:// www.gks.ru/bgd/regl/b15_102/Main.htm (дата обращения: 10 мая 2019).

Росстат (2017) Российский статистический ежегодник. Статистический сборник. Доступно по ссылке: http://www.gks.ru/free_doc/doc_2017/year/year17.pdf (дата обращения 15 июня 2018). 
Счетная палата РФ (2015) Заключение на проект федерального закона «О бюджете Федерального фонда обязательного медицинского страхования на 2016 год». Доступно по ссылке: http:/audit.gov.ru/upload/iblock/ea8/ea87b37e58940b7d698451a80abd8e22.doc (дата обращения: 29 октября 2017).

Шейман И. М., Шевский В.И. (2015) Кадровая политика в здравоохранении: сравнительный анализ российской и международной практики. Bonpocbl государственного и мyниципального управления, (1): 143-167.

Шишкин С.В., Потапчик Е.Г., Селезнева Е.В. (2014) Оплата пацииентами медицинской помощи в российской системе здравоохранения. М.: Изд. дом Высшей школы экономики.

Allin S., Masseria C., Sorenson C., Papanicolas I., Mossialos E. (2007) Measuring Inequalities in Access to Health Care. A Review of the Indices. Available at: http://ec.europa.eu/employment_social/social_situation/docs/rn_access_to_care.pdf (accessed 29 October 2017).

Chaupain-Guillot S., Guillot O. (2015) Health System Characteristics and Unmet Care Needs in Europe: An Analysis Based on EU-SILC Data. The European Journal of Health Economics, (16): 781-796.

Eurofound (2014) Access to Healthcare in Times of Crisis. Luxembourg: Office of the European Union.

European Commision (2013) Evaluation of the Use and Impact of the European Community Health Indicators/ECHI by Member States. Final report. Available at: http://ec.europa.eu/health/indicators/docs/echi_report_v20131031.pdf(accessed 29 October 2017).

Eurostat (2014) Unmet Health Care Needs Statistics. Available at: http://ec.europa.eu/eurostat/statistics-explained/images/a/a5/Unmet_health_care_needs_statistics_2014_final.xlsx (accessed 29 October 2017).

Gelormino E., Bambra C., Spadea T., Bellini S., Costa G. (2011) The Effects of Health Care Reforms on Health Inequalities: A Review and Analysis of the European Evidence Base. International Journal of Health Services, (41): 209-230.

Lalonde M. (1974) New Perspective on the Health of Canadians. A Working Document. Ottawa: Government of Canada.

OECD (2009) Health at a Glance 2009: OECD Indicators. Available at: http://dx.doi.org/10.1787/ health_glance-2009-en (accessed 29 October 2017).

OECD (2014) Health at a Glance: Europe 2014. Available at: http://dx.doi.org/10.1787/health glance_eur-2014-en (accessed 29 October 2017).

OECD (2016a) Health at a Glance: Europe 2016: State of Health in the EU Cycle. Available at: http://dx.doi.org/10.1787/9789264265592-en (accessed 29 October 2017).

OECD (2016b) Health Workforce Policies in OECD Countries: Right Jobs, Right Skills, Right Places. Available at: http://dx.doi.org/10.1787/9789264239517-en (accessed 29 October 2017).

Ono T., Schoenstein M., Buchan J. (2014) Geographic Imbalances in Doctor Supply and Policy Responsesю. OECD Health Working Papers, No. 69, OECD Publishing Paris. Available at: http://dx.doi.org/10.1787/5jz5sq51s1wl-en (accessed 10 May 2019).

Xu K., Saksena P., Jowett M., Indikadahena C., Kutzin J., Evans D. (2010) Exploring the Thresholds of Health Expenditure for Protection against Financial Risk. World Health Report. Background Paper, No 19.

Wörz M., Foubister T., Busse R. (2006) Access to Health Care in the EU Member States. Euro Observer, 8 (2): 1-4.

WHO (2016) European Health for all database (HFA-DB). Available at: http://data.euro.who. int/ (accessed 29 October 2017). 


\section{ACCESS TO HEALTHCARE: RUSSIA IN THE EUROPEAN CONTEXT}

The present article investigates access to healthcare in Russia and the EU countries. Indicators to access include healthcare coverage, private medical care expenses, the geographic distribution of doctors, and unmet health care needs. A comparative analysis of access to medical services in Russia and European countries on the basis of these indicators leads to a number of conclusions. Firstly, Russia, like in the vast majority of European countries, has achieved universal (or near-universal) healthcare coverage. On the other hand, the basic package guaranteed by state healthcare is insufficient for the needs of the population. This is evidenced by the significant increase over the past fifteen years of private medical care expenses among the Russian population, while in most EU countries this has remained stable. Secondly, the geographic distribution of doctors in Russia is such that the provision of doctors in cities far exceeds that of rural areas, while in the countries of the European Union there is a more even distribution of medical personnel. Thirdly, the optimization of human resources for health care, conducted in recent years, does not lead Russia to the average European level. The unsatisfactory organization of medical care for rural areas reduces access to medical services for rural residents. Reports of assessing the unmet healthcare needs of Russian and European citizens show that the proportion of those in Russia who cannot access health care due to problematic transport accessibility or financial reasons is many times higher than the developed countries of Europe.

Keywords: healthcare, access, barrier filter, European Union, Russia

DOI: 10.17323/727-0634-2019-17-2-177-190

\section{References}

Allin S., Masseria C., Sorenson C., Papanicolas I., Mossialos E. (2007) Measuring Inequalities in Access to Health Care. A Review of the Indices. Available at: http://ec.europa.eu/employment_social/social_situation/docs/rn_access_to_care.pdf (accessed 29 October 2017).

Chaupain-Guillot S., Guillot O. (2015) Health System Characteristics and Unmet Care Needs in Europe: An Analysis Based on EU-SILC Data. The European Journal of Health Economics, (16): 781-796.

European Commission (2013) Evaluation of the Use and Impact of the European Community Health Indicators/ ECHI by Member States. Final report. Available at: http://ec.europa.eu/health/indicators/docs/echi_report_v20131031.pdf (accessed 29 October 2017).

Ludmila Panova - PhD (kandidat nauk) in Economy, Senior Researcher, Sociological Institute of the Federal Center of Theoretical and Applied Sociology of the Russian Academy of Science, St. Petersburg, Russian Federation. Email: 1_panova@list.ru 
Eurofound (2014) Access to Healthcare in Times of Crisis. Luxembourg: Office of the European Union. Available at: https://www.eurofound.europa.eu/publications/report/2014/ quality-of-life-social-policies/access-to-healthcare-in-times-of-crisishttps:/www.eurofound.europa.eu/publications/report/2014/quality-of-life-social-policies/access-to-healthcare-in-times-of-crisishttps://www.eurofound.europa.eu/publications/report/2014/qualityof-life-social-policies/access-to-healthcare-in-times-of-crisis (accessed 27 May 2019).

Eurostat (2014) Unmet Health Care Needs Statistics. Available at: http://ec.europa.eu/eurostat/statistics-explained/images/a/a5/Unmet_health_care_needs_statistics_2014_final.xlsx (accessed 29 October 2017).

Gelormino E., Bambra C., Spadea T., Bellini S., Costa G. (2011) The Effects of Health Care Reforms on Health Inequalities: A Review and Analysis of the European Evidence Base. International Journal of Health Services, (41): 209-230.

Lalonde M. (1974) New Perspective on the Health of Canadians. A Working Document. Ottawa: Government of Canada.

The Ministry of Agriculture of the Russian Federation (2014) Sostoyanie sotsial'no-trudovoy sfery sela i predlozheniya po ee regulirovaniyu [The State of the Social and Labor Sphere of the Village and Proposals for its Regulation]. Ezhegodnyy doklad po rezul'tatam monitoringa 2013 g. [Annual Report on Monitoring Results 2013]. Issue 15. Moscow: Rosinformagrotekh.

The Ministry of Agriculture of the Russian Federation (2018) O sostoyanii sel'skikh territoriy v Rossiyskoy Federatsii v 2016 godu [On the State of Rural Areas in the Russian Federation in 2016]. Ezhegodnyy doklad po rezul'tatam monitoringa [Annual Report on Monitoring Results]. Issue 4. Moscow: Rosinformagrotekh.

OECD (2009) Health at a Glance 2009: OECD Indicators. Available at: http://dx.doi.org/10.1787/ health_glance-2009-en (accessed 29 October 2017).

OECD (2014) Health at a Glance: Europe 2014. Available at: http://dx.doi.org/10.1787/ health_glance_eur-2014-en (accessed 29 October 2017).

OECD (2016a) Health at a Glance: Europe 2016: State of Health in the EU Cycle. Available at: http://dx.doi.org/10.1787/9789264265592-en (accessed 29 October 2017).

OECD (2016b) Health Workforce Policies in OECD Countries: Right Jobs, Right Skills, Right Places. Available at: http://dx.doi.org/10.1787/9789264239517-en (accessed 29 October 2017).

Ono T., Schoenstein M., Buchan J. (2014) Geographic Imbalances in Doctor Supply and Policy Responsesю. OECD Health Working Papers, No. 69, OECD Publishing Paris. Available at: http://dx.doi.org/10.1787/5jz5sq51s1wl-en (accessed 10 May 2019).

Rosstat (2007) Dokhody, raskhody i potreblenie domashnikh khozyaystvv 2007 g. (po itogam vyborochnogo obsledovaniya byudzhetov domashnikh khozyaystv) [Incomes, Expenditures and Consumption of Households in 2007 (Based on the Results of a Sample Survey of Household Budgets]. Available at: http://www.gks.ru/bgd/regl/B07_102/Main.htm (accessed 10 May 2019).

Rosstat (2014) Kompleksnoe nablyudenie usloviy zhizni naseleniya [Comprehensive Monitoring of Living Conditions]. Available at: http://www.gks.ru/free_doc/new_site/KOUZ14/ survey0/index.html (accessed 29 October 2017). 
Rosstat (2015) Dokhody, raskhody i potreblenie domashnikh khozyaystv v 2007 g. (po itogam vyborochnogo obsledovaniya byudzhetov domashnikh khozyaystv) [Incomes, Expenditures and Consumption of Households in 2015 (Based on the Results of a Sample Survey of Household Budget's]. Available at: http://www.gks.ru/bgd/regl/b15_102/Main.htm (accessed 10 May 2019).

Rosstat (2017) Rossiyskiy statisticheskiy ezhegodnik. Statisticheskiy sbornik [Russian Statistical Yearbook. Statistical Handbook]. Available http://www.gks.ru/free_doc/doc_2017/ year/year17.pdf (accessed 15 June 2018).

Schejman I.M., Schewckij W.I. (2015) Kadrowaja politika w sdrawoochranenii: crawnitel'nyj analis roccijckoj i mezhdunarodnoj praktiki. Woprocy gocudarctwennogo i munizipal'nogo uprawlenija, (1): 143-167.

Shishkin S. V., Potapchik E. G., Selezneva E. V. (2014) Oplata patsientami meditsinskoy pomoshchi v rossiyskoy sisteme zdravookhraneniya [Out-of-pocket Payments in the Russian Health Care System]. Moscow: Izd. dom Vysshey shkoly ekonomiki.

The Accounts Chamber of the Russian Federation (2015) Zaklyuchenie na proekt federal'nogo zakona 'O byudzhete Federal'nogo fonda obyazatel'nogo meditsinskogo strakhovaniya na 2016 god' [Conclusion of the Draft Federal Law 'On The Budget of the Federal Fund for Mandatory Medical Insurance for 2016']. Available at: http://audit.gov.ru/upload/iblock/ ea8/ea87b37e58940b7d698451a80abd8e22.doc (accessed 29 October 2017).

The Government of the Russian Federation (2016) O programme gosudarstvennykh garantiy besplatnogo okazaniya grazhdanam meditsinskoy pomoshchi na 2017 god i na planovyy period 2018 i 2019 godov [Program of State Guarantees of Free Provision to Citizensmedical Assistance for 2017 and for the Planning Period 2018 and 2019]. Available at: http://www.rgs. $\mathrm{ru} /$ upload/medialibrary/313/programma-gosudarstvennykh-garantiy-besplatnogo-okazaniya-grazhdanam-meditsinskoy-pomoshchi-na-2017-god-i-na-planovyy-period-2018-i-2019-godov.pdf (accessed 29 October 2017).

Xu K., Saksena P., Jowett M., Indikadahena C., Kutzin J., Evans D. (2010) Exploring the Thresholds of Health Expenditure for Protection against Financial Risk. World Health Report. Background Paper, No 19. Available at: https://www.cpc.unc.edu/projects/rlms-hse/ publications/2066 (accessed 27 May 2019).

WHO (2016) European Health for all database. Available at: http://data.euro.who.int/ (accessed 29 October 2017). 